\title{
The Orexin-I Receptor Antagonist SB-334867 Blocks the Effects of Antipsychotics on the Activity of $A 9$ and Al0 Dopamine Neurons: Implications for Antipsychotic Therapy
}

\author{
Kurt Rasmussen*,', Mei-Ann Hsu' and Yili Yang' \\ 'Lilly Research Laboratories, Eli Lilly and Company, Lilly Corporate Center, Indianapolis, IN, USA
}

Antipsychotic drugs alter the activity of dopamine neurons in the ventral tegmental area (AI0) and substantia nigra pars compacta (A9). As there is a dense projection of orexin neurons from the lateral hypothalamus to Al0 dopaminergic neurons, and some antipsychotics have been shown to increase the expression of c-fos in orexin-containing cells in the hypothalamus, we hypothesized that stimulation of orexin receptors plays a role in the effects of antipsychotics on the activity of A9 and Al0 dopamine cells. Single-unit recordings in anesthetized rats demonstrated the central effects of the selective orexin-I receptor antagonist SB-334867 (2 mg/kg, intravenous), as it reversed the excitatory effects of orexin-A administration ( $6 \mu \mathrm{g}$, intracerebroventricular) on the activity of locus coeruleus (LC) cells. Recordings from midbrain dopamine neurons showed that acute administration of SB-334867 alone did not alter the number of spontaneously active A9 or A 10 cells, but did reverse: (I) the increase in the number of spontaneously active A9 and/or A I0 dopamine cells caused by the acute administration of haloperidol (I mg/kg, subcutaneous) or olanzapine (I0 mg/kg, s.c.) and (2) the decrease in the number of spontaneously active A9 and/or A I0 dopamine cells caused by the chronic administration of haloperidol $(\mathrm{I} \mathrm{mg} / \mathrm{kg} / \mathrm{day} \times 2 \mathrm{I}$ days, s.c.) or olanzapine $(10 \mathrm{mg} / \mathrm{kg} / \mathrm{day} \times 21$ days, s.c.). However, SB-334867 did not block a different electrophysiological effect of olanzapine, as it did not block the olanzapine-induced activation of LC cells. These results indicate that activation of orexin-I receptors plays an important role on the effects of antipsychotic drugs on dopamine neuronal activity and may play an important role in the clinical effects of antipsychotic drugs.

Neuropsychopharmacology (2007) 32, 786-792. doi: I 0.1038/sj.npp. I 301239; published online 25 October 2006

Keywords: antipsychotics; orexin; dopamine; hypocretin; olanzapine; haloperidol

\section{INTRODUCTION}

Orexin-A (also known as hypocretin 1) and orexin-B (also known as hypocretin 2) are two neuropeptides derived from the precursor prepro-orexin (Sakurai et al, 1998). The cell bodies of orexin-containing neurons are located in the hypothalamus and send extensive projections to many brain areas. Receptors for orexin-A and orexin-B are G-protein coupled and are divided into two types: orexin-1 and orexin-2. Orexin-A has a ten-fold higher affinity than orexin-B for the orexin-1 receptor, whereas orexin-A and orexin-B have equal affinity for the orexin-2 receptor (Smart et al, 1999, 2000). The orexin system has been hypothesized to play a role in a number of brain functions including modulation of the neuroendocrine system, con-

*Correspondence: Dr K Rasmussen, Lilly Research Laboratories, Eli Lilly and Company, Lilly Corporate Center, Indianapolis, IN 46285, USA, Tel: + I 317277 8835, Fax: + I 3172765546 ,

E-mail: rasmussen_kurt@lilly.com

Received 28 April 2006; revised II September 2006; accepted 13 September 2006

Online publication: 21 September 2006 at http://www.acnp.org/ citations/Npp092 106060278/default.pdf trol of feeding and energy metabolism, and regulation of the sleep-wake cycle (Sakurai et al, 1998; Van den Pol et al, 1998; Piper et al, 2000). Recently, a selective antagonist of orexin-1 receptors, SB-334867, has been described (Smart et al, 2001).

Administration of antipsychotics has been shown to alter the activity of dopamine neurons in the ventral tegmental area (VTA) (A10) and the substantia nigra pars compacta (A9). Acute administration of typical antipsychotic drugs (eg haloperidol) increases the number of spontaneously active A10 and A9 dopamine cells. However, acute administration of atypical antipsychotics (eg olanzapine) selectively increases the number of spontaneously active A10, but not A9, dopamine cells (Chiodo and Bunney, 1983; Stockton and Rasmussen, 1996). Repeated administration of haloperidol leads to depolarization inactivation and a decrease in the number of spontaneously active A9 and A10 dopamine cells (Bunney and Grace, 1978; Chiodo and Bunney, 1983; White and Wang, 1983). Similarly, repeated administration of olanzapine leads to a decrease in the number of spontaneously active A10, but not A9, dopamine cells (Stockton and Rasmussen, 1996). These effects on A9 and A10 dopamine neuronal activity have 
been hypothesized to play a role in the clinical effects of antipsychotic drugs. Atypical antipsychotics differ from typical antipsychotics in a number of ways, including having a decreased propensity to produce extrapyramidal motor side effects. The common actions of typical and atypical antipsychotics on A10 dopamine cells has been hypothesized to play a role in the therapeutic efficacy of the drugs, whereas the effects of typical antipsychotics on A9 dopamine cells has been hypothesized to play a role in the extrapyramidal motor side effects of the drugs (Bunney and Grace, 1978; Chiodo and Bunney, 1983; White and Wang, 1983).

As there is a dense projection of orexin neurons from the lateral hypothalamus to A10 dopaminergic neurons (Fadel and Deutch, 2002) and some antipsychotics have been shown to increase the expression of c-fos in orexincontaining cells in the hypothalamus (Fadel et al, 2002), we hypothesized that the activation of orexin receptors plays a role in the effects of antipsychotics on A9 and A10 dopamine cells. We examined the effects of the selective orexin-1 receptor antagonist SB-334867 on the effects of acute and chronic (21 days) administration of the typical antipsychotic haloperidol and the atypical antipsychotic olanzapine on the number of spontaneously active A9 and A10 dopamine cells. To determine a centrally active dose of SB-334867, we first examined the effects of SB-334867 on the excitatory effects of intracerebrovascular administration of orexin A on locus coeruleus (LC) neuronal activity. In addition, to check to see whether SB-334867 affected the electrophysiological effects of olanzapine in a different brain area, we examined the effects of SB-334867 on the excitatory effects of olanzapine administration on LC neuronal activity.

\section{MATERIALS AND METHODS}

\section{Animals}

Male Sprague-Dawley rats were obtained from Harlan Industries (Indianapolis, IN) and weighed 280-330 g at the time of electrophysiological recording. Animals were group housed upon arrival and food and water were available ad lib. A 12:12 light:dark cycle was maintained in the colony room. All procedures were carried out in accordance with the National Institutes of Health's Guide for the Care and Use of Laboratory Animals and were approved by the Eli Lilly Animal Care and Use Committee.

\section{Drug Solutions}

Olanzapine (Eli Lilly and Company, Indianapolis, IN) and haloperidol (Sigma, St Louis, MO) were dissolved in a combination of $5 \%$ lactic acid, sodium hydroxide, and distilled water (final $\mathrm{pH}$ 5.8). SB-334867 (Eli Lilly and Company, Indianapolis, IN) was dissolved in $50 \%$ (2hydroxypropyl)- $\beta$-cyclodextrin (Sigma, St Louis, MO). Orexin-A (California Peptide Research, Napa, CA) was dissolved in distilled water.

\section{Electrophysiological Recordings}

Rats were anesthetized with chloral hydrate $(400 \mathrm{mg} / \mathrm{kg}$, i.p.); supplemental doses of anesthetic were administered through the lateral tail vein as needed. Body temperature was maintained at $37^{\circ} \mathrm{C}$ by a heating pad. The anesthetized rats were mounted in a stereotaxic apparatus, the skull exposed, and a cisternal drain performed to prevent tissue swelling. A burr hole was made in the skull. Electrodes were fabricated from $2.0 \mathrm{~mm}$ O.D. capillary tubing (Radnoti, Monrovia, CA) on a Narishige (Tokyo, Japan) electrode puller (model PE-2). Electrodes were filled with a $2 \mathrm{M} \mathrm{NaCl}$ solution and broken back to impedances of 2.0-3.0 M $\Omega$. The recording electrode was advanced, using a micropositioning device (Burleigh, Inchworm Motor Controller, Victor, NY), in $5 \mu \mathrm{m}$ increments through the nucleus of study. Activity from the electrode was monitored via an oscilloscope and audio monitor, band-pass filtered $(300-3000 \mathrm{~Hz}$; Dagan model 2400, Minneapolis, MN), and passed through a Micro1401 data acquisition unit connected to a computer running Spike2 software (Cambridge Electronic Design, Cambridge, UK). A software window discriminator was set to capture only the largest amplitude unit in the recording. Only data from cells where stable recordings were obtained ( $>60 \mathrm{~s}$ ) were used for analysis.

Dopamine cells. The electrode was passed through nine tracks (each track was separated by $0.2 \mathrm{~mm}$ ), in a sterotaxically defined block of tissue $(5.0-5.4 \mathrm{~mm}$ posterior and $2.0-2.4 \mathrm{~mm}$ lateral to the bregma, and $6.0-8.5 \mathrm{~mm}$ ventral to the cortical surface for A9; and $5.0-5.4 \mathrm{~mm}$ posterior and $0.5-0.9 \mathrm{~mm}$ lateral to the bregma, and $6.0-8.5 \mathrm{~mm}$ ventral to the cortical surface for A10), and the number of spontaneously active dopamine cells was counted. Each dopamine cell was recorded for 3-5 min. The electrode tracks were made in a preset sequence that was kept constant from animal to animal. For acutely treated animals, three control tracks were scored before drug treatment. Animals were then treated with either olanzapine (10 mg/kg, subcutaneous), haloperidol (1 mg/kg, s.c.), or vehicle and, beginning $1 \mathrm{~h}$ later, three additional tracks were recorded. Animals were subsequently treated with either SB-334867 (2 mg/kg, intravenous) or vehicle and three additional tracks were recorded beginning immediately. For chronically-treated animals, osmotic minipumps (Alzet model 2ML2, flow rate $5 \mu \mathrm{l} / \mathrm{h}$; Durect Corp, Cupertino, CA) delivering vehicle, olanzapine $(10 \mathrm{mg} / \mathrm{kg} /$ day $)$, or haloperidol ( $1 \mathrm{mg} / \mathrm{kg} /$ day) were implanted under isoflurane (5\%) anesthesia. Rats were reimplanted with new pumps 2 weeks after the first implant procedure. After 21 days, six tracks were recorded in either A9 or A10. Animals were then treated with SB-334867 (2 mg/kg, i.v.) or vehicle and three additional tracks were recorded. Only one area, either A9 or A10, was recorded in each chronically treated animal. The firing rate and proportion of spikes that occurred in bursts (defined as the occurrence of two spikes with an interspike interval $<80 \mathrm{~ms}$, with the termination as the occurrence of an interspike interval of $>160 \mathrm{~ms}$ ) for each spontaneously active dopamine cell was also recorded. Spontaneously active dopamine cells were recorded as previously reported (Chiodo and Bunney, 1983; White and Wang, 1983; Stockton and Rasmussen, 1996). Briefly, cells were considered dopaminergic if they possessed the following characteristics: (1) action potential duration of $2.5-4.5 \mathrm{~ms}$, (2) triphasic waveform containing a notch in the initial rising phase of the first positive peak, and (3) slow, slightly 
irregular firing pattern, with a rate of $2-10 \mathrm{~Hz}$. Previously, these characteristics have been demonstrated to be shown only by dopaminergic neurons (Bunney et al, 1973).

LC cells. Recordings were made unilaterally and electrode tracks were 0.1-0.2 mm apart. Characteristics of LC neurons have been described previously (Graham and Aghajanian, 1971), and the criteria for inclusion in the current study were a regular firing rate with a positive-negative action potential of long duration $(\sim 2 \mathrm{~ms})$, and a burst of action potentials, followed by a period of quiescence in response to a pinch of the contralateral hind paw. To examine the effects of SB-334867 on the acute administration of olanzapine on LC cells, a dose of olanzapine that has previously been shown to produce robust increases in LC firing $(3 \mathrm{mg} / \mathrm{kg}$, i.v.) was chosen (Dawe et al, 2001; Seager et al, 2004).

\section{I.C.V. Injections}

A small hole was made in the skull with a 22 -gauge needle above the lateral ventricle $(1.0 \mathrm{~mm}$ posterior and $1.5 \mathrm{~mm}$ lateral to the bregma). The tip of a $25-\mu$ l Hamilton syringe was lowered $3.5 \mathrm{~mm}$ from the top of skull. Orexin-A $(6 \mu \mathrm{g}$ in $6 \mu \mathrm{l})$ or its vehicle was administered slowly through the syringe $(1 \mu \mathrm{l} / \mathrm{min})$. For verification of the injection site, methylene blue was delivered through the syringe at the end of each experiment.

\section{Data Analysis}

Results were analyzed using either paired $t$-tests, with each animal serving as its own control, or one-way analysis of variance coupled with the Tukey-Kramer post hoc test.

\section{RESULTS}

Administration of orexin-A ( $6 \mu$ g, i.c.v.) led to a significant $(p<0.05)$ increase in the activity of LC cells (Figure 1$)$. Subsequent injection of SB-334867 (2 mg/kg, i.v.), but not vehicle, reversed the effect of orexin- $A$ and returned the firing of the cells to baseline levels. Lower doses of SB$334867(0.5,1.0 \mathrm{mg} / \mathrm{kg}$, i.v. $)$ did not fully reverse the effects of orexin-A (data not shown).

Acute administration of SB-334867 ( $2 \mathrm{mg} / \mathrm{kg}$, i.v.) did not significantly alter the number of spontaneously active A9 or A10 dopamine neurons (Figure 2; $n=6$ per group) nor the firing rate nor burst activity of these neurons (data not shown). The baseline firing rates for A9 and A10 dopamine cells were $2.9 \pm 0.3 \mathrm{~Hz}(n=16)$ and $2.9 \pm 0.4 \mathrm{~Hz}(n=13)$, respectively. The baseline percentage of spikes in bursts for A9 and A10 dopamine cells were $5.3 \pm 2.0(n=17)$ and $18.5 \pm 4.6(n=26)$, respectively.

Acute administration of haloperidol $(1 \mathrm{mg} / \mathrm{kg}$, s.c.; $n=10$ animals) significantly $(p<0.01)$ increased the number of spontaneously active A9 $(n=5$ animals $)$ and A10 $(n=5$ animals) dopamine cells (Figure 3). Subsequent administration of SB-334867 (2 mg/kg, i.v.) blocked the effects of haloperidol and returned the number of spontaneously active A9 and A10 dopamine cells to baseline levels. Neither acute administration of haloperidol nor subsequent administration of SB-334867 significantly altered the firing rate or

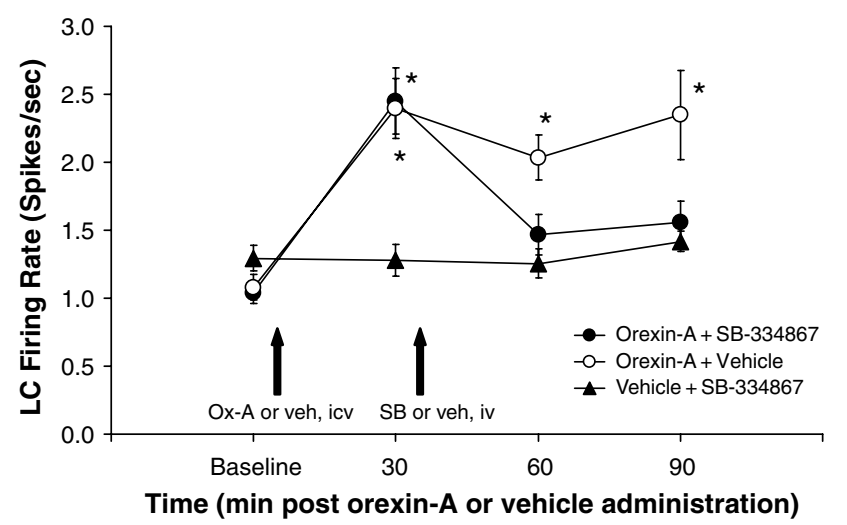

Figure I Effects of orexin-A (Ox-A; $6 \mu$ g, i.c.v.) or vehicle (veh; $6 \mu$, i.c.v.) followed $30 \mathrm{~min}$ later by administration of the selective orexin- I antagonist SB-334867 (SB; $2 \mathrm{mg} / \mathrm{kg}$, i.v.) or vehicle (veh) on the firing rate of locus coeruleus (LC) neurons. $N=10-33$ cells per point. *Significantly different from baseline $(p<0.05)$.

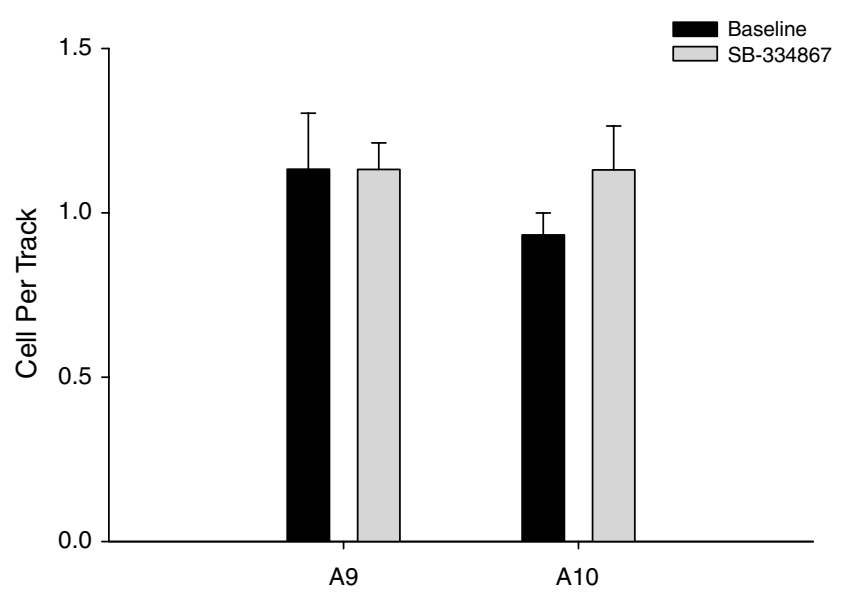

Figure 2 Effect of acute administration of SB-334867 $(2 \mathrm{mg} / \mathrm{kg}$, i.v. $)$ on the number of $\mathrm{A} 9$ and $\mathrm{Al} 0$ dopamine cells per track in animals receiving chronic vehicle. $N=6$ animals per group.

burst activity of A9 or A10 dopamine neurons (data not shown).

Acute administration of olanzapine $(10 \mathrm{mg} / \mathrm{kg}$, s.c.) significantly $(p<0.01)$ increased the number of spontaneously active A10 $(n=5)$, but not A9 $(n=5)$, dopamine cells (Figure 4). Subsequent administration of SB-334867 $(2 \mathrm{mg} / \mathrm{kg}$, i.v.) did not alter the number of spontaneously active A9 dopamine cells, but blocked the effects of olanzapine and returned the number of spontaneously active A10 dopamine cells to baseline levels. Neither acute administration of olanzapine nor subsequent administration of SB-334867 significantly altered the firing rate or burst activity of A9 or A10 dopamine neurons (data not shown).

Administration of haloperidol $(1 \mathrm{mg} / \mathrm{kg} /$ day, s.c.; $n=6$ animals) for 21 days significantly $(p<0.01)$ decreased the number of spontaneously active A9 and A10 dopamine cells (Figure 5), but did not change the firing rate nor burst activity of A9 and A10 dopamine cells. Acute administration of SB-334867 (2 mg/kg, i.v.) reversed the effects of haloperidol on the number of spontaneously active A9 and A10 dopamine cells. Neither repeated administration of 

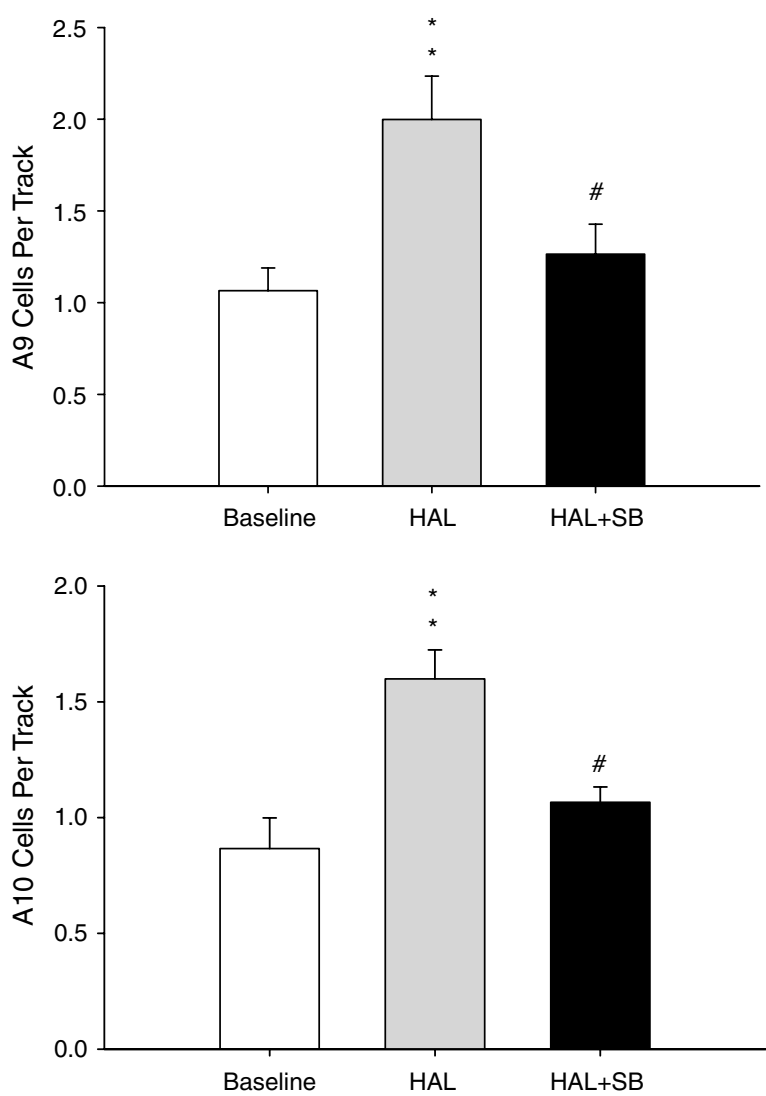

Figure 3 Effect of acute administration of haloperidol (HAL; I mg/ $\mathrm{kg}$, s.c.) followed by administration of SB-334867 (SB; $2 \mathrm{mg} / \mathrm{kg}$, i.v.) on the number of $A 9$ (top) and $\mathrm{AlO}$ (bottom) dopamine cells per track. ** Significantly different from baseline $(p<0.0 \mathrm{l})$; ${ }^{\#}$ significantly different from haloperidol alone $(p<0.05) ; N=5$ animals per group.

haloperidol nor subsequent acute administration of SB334867 significantly altered the firing rate or burst activity of A9 or A10 dopamine neurons (data not shown).

Administration of olanzapine $(10 \mathrm{mg} / \mathrm{kg} /$ day, s.c.; $n=6$ animals) for 21 days significantly $(p<0.01)$ decreased the number of spontaneously active A10, but not A9, dopamine cells (Figure 6), but did not change the firing rate nor burst activity of A9 and A10 dopamine cells. Acute administration of SB-334867 $(2 \mathrm{mg} / \mathrm{kg}$, i.v.), did not alter the number of spontaneously active A9 dopamine cells, but did reverse the effects of olanzapine on the number of spontaneously active A10 dopamine cells. Neither repeated administration of olanzapine nor subsequent acute administration of SB334867 significantly altered the firing rate or burst activity of A9 or A10 dopamine neurons (data not shown).

Acute administration of olanzapine $(3 \mathrm{mg} / \mathrm{kg}$, i.v.) significantly $(p<0.05)$ increased the firing rate of LC cells $(n=6$; Figure 7). Subsequent administration of SB-334867 $(2 \mathrm{mg} / \mathrm{kg}$, i.v.) did not alter the effects of olanzapine on the activity of LC cells.

\section{DISCUSSION}

Administration of the orexin-1 receptor antagonist SB334867 reversed the effects of acute and chronic administration of both haloperidol and olanzapine on A9 and A10
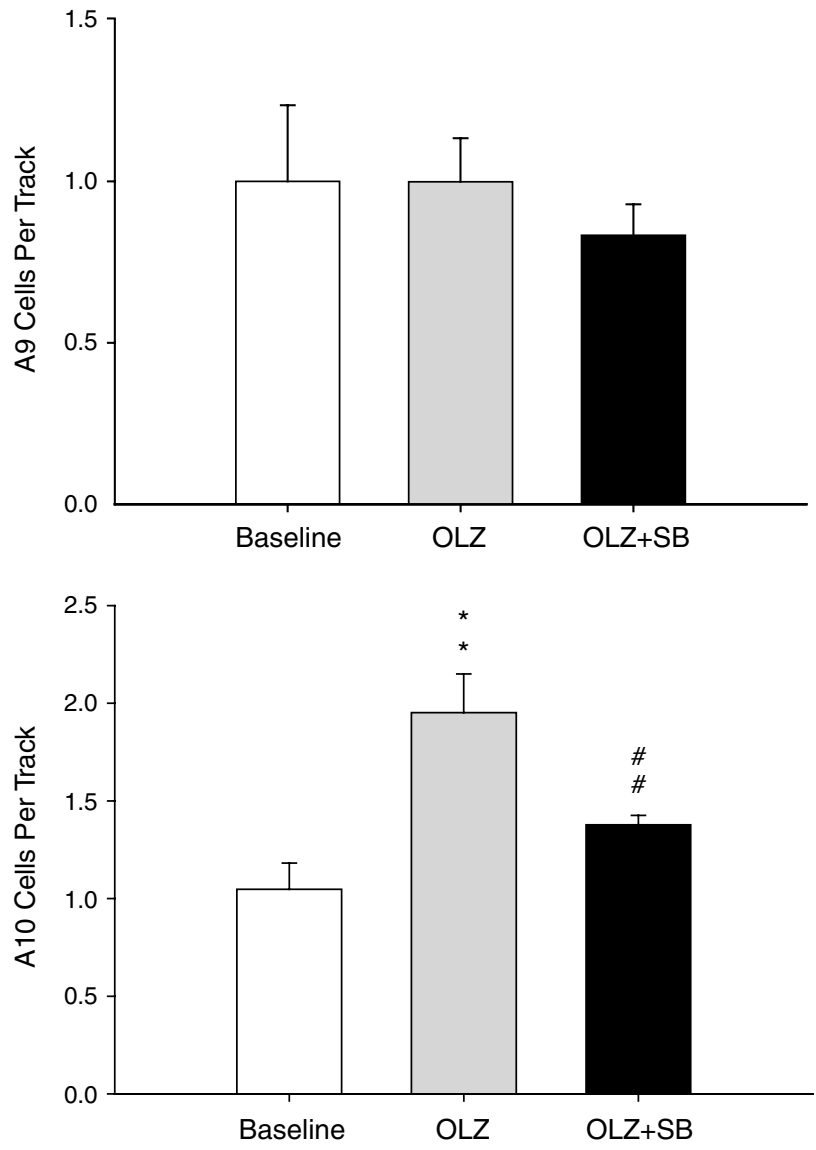

Figure 4 Effect of acute administration of olanzapine $(\mathrm{OLZ} ; 10 \mathrm{mg} / \mathrm{kg}$, s.c.) followed by administration of SB-334867 (SB; $2 \mathrm{mg} / \mathrm{kg}$, i.v.) on the number of $A 9$ (top) and $A 10$ (bottom) dopamine cells per track. ** Significantly different from baseline $(p<0.01)$; ${ }^{\# \#}$ significantly different from olanzapine alone $(p<0.0 \mathrm{I}) ; N=5$ animals per group.

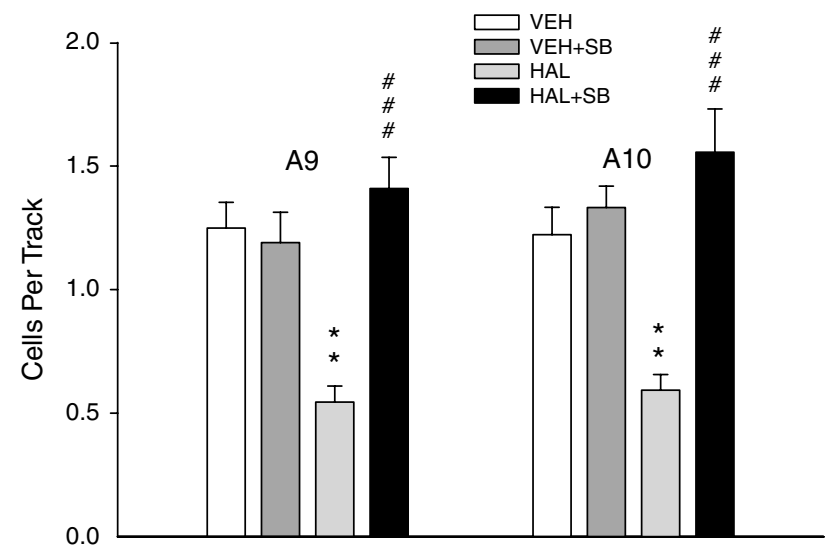

Figure 5 Effect of chronic administration of haloperidol (HAL; I mg/kg/ day, s.c. $\times 2$ I days) or vehicle (VEH) and acute administration of SB334867 (SB; $2 \mathrm{mg} / \mathrm{kg}$, i.v.) on the number of A9 and AI0 dopamine cells per track. **Significantly different from chronic vehicle group $(p<0.0 \mathrm{I})$;

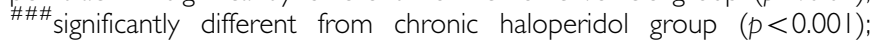
$N=6-1 \mid$ animals per group.

dopamine neurons. Effects on the activity of A9 and A10 dopamine cells have been hypothesized to play an important role in the clinical effects of both typical and atypical antipsychotic drugs. The common effect of typical 


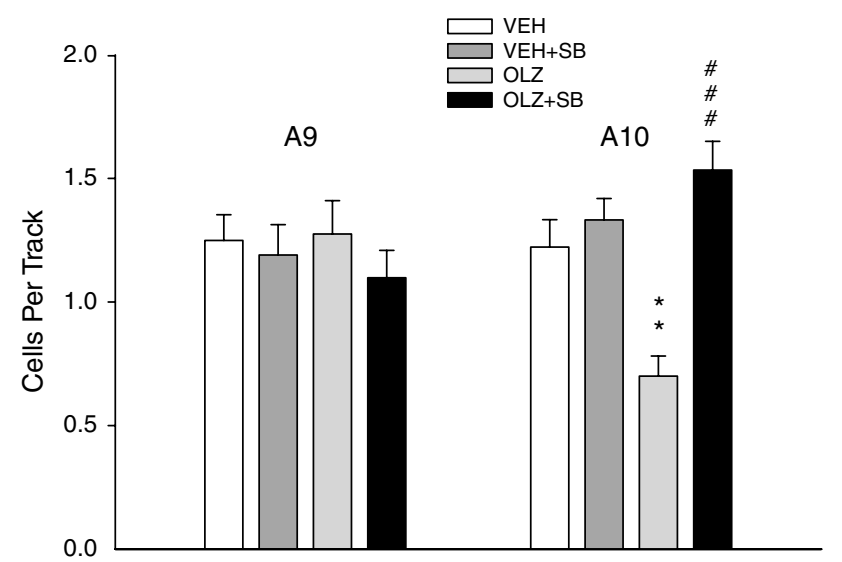

Figure 6 Effect of chronic administration of olanzapine $(O L Z ; 10 \mathrm{mg} / \mathrm{kg} /$ day, s.c. $\times 21$ days) or vehicle $(\mathrm{VEH})$ and acute administration of SB334867 (SB; $2 \mathrm{mg} / \mathrm{kg}$, i.v.) on the number of A9 and AI0 dopamine cells per track. **Significantly different from chronic vehicle group $(p<0.01)$; \#\#\# significantly different from chronic olanzapine group $(p<0.00 \mathrm{I})$; $N=6-10$ animals per group.

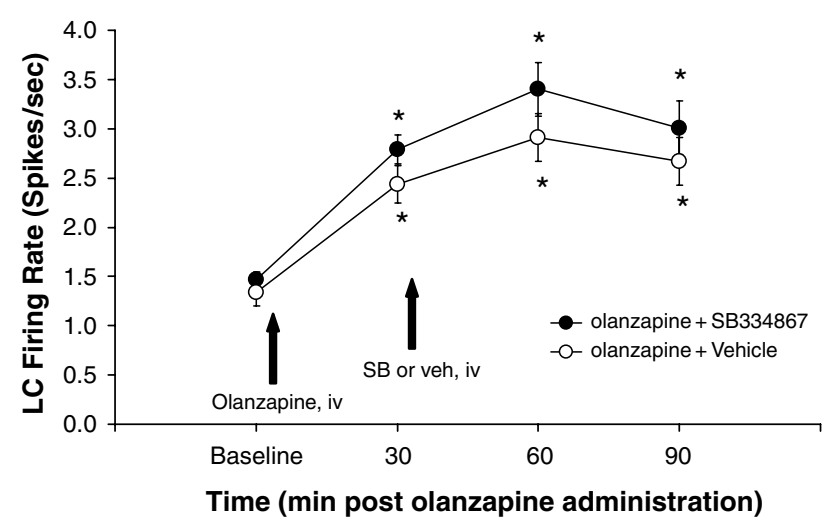

Figure 7 Effects of olanzapine ( $3 \mathrm{mg} / \mathrm{kg}$, i.v.) followed $30 \mathrm{~min}$ later by administration of the SB-334867 (SB; $2 \mathrm{mg} / \mathrm{kg}$, i.v.) or vehicle (veh) on the firing rate of locus coeruleus (LC) neurons. *Significantly different from baseline $(p<0.05) ; N=5$ animals per group.

and atypical antipsychotics on the activity of A10 dopamine neurons has been proposed to mediate their therapeutic efficacy, whereas the effect of typical antipsychotics on A9 dopamine activity has been proposed to mediate the extrapyramidal side effects of these drugs (Bunney and Grace, 1978; Chiodo and Bunney, 1983; White and Wang, 1983). If these hypotheses are correct, then the present results indicate that orexin-1 receptor antagonists may block the efficacy of antipsychotic drugs by blocking their action on A10 dopamine cells and block the motor side effects of antipsychotic drugs by blocking their action of A9 dopamine neurons. In this regard, the NK-3 antagonist SR142801 also was shown to block the effects of acute and chronic administration of haloperidol on A9 and A10 activity (Gueudet et al, 1999). In clinical trials, SR142801 displayed some degree of antipsychotic efficacy, albeit less than haloperidol, and caused fewer extrapyramidal symptoms than haloperidol (Meltzer et al, 2004). However, an interaction of haloperidol and SR142801 was not examined in these clinical trials. Only clinical trials with orexin-1 receptor antagonists will be able to determine their effects on antipsychotic efficacy and side effects.

The locus of action of the effects of SB-334867 cannot be determined from this study. Direct hyperpolarization of dopamine neurons can reverse antipsychotic-induced depolarization inactivation (Bunney and Grace, 1978; Chiodo and Bunney, 1983). As SB-334867 does not alter the number of cells per track (Figure 2) or the firing rate and activity of individual A9 and A10 cells (data not shown) in control animals, it seems unlikely that it is reversing the effects of antipsychotic drugs by directly hyperpolarizing dopamine cells. However, it is possible that SB-334867 is having effects directly on A10 dopamine neurons, as there is a dense projection of orexin neurons from the lateral hypothalamus to A10 dopaminergic neurons (Fadel and Deutch, 2002) and direct application of orexins can activate at least a subpopulation of VTA dopamine (and nondopamine) cells (Korotkova et al, 2003). Further, orexin-A induces a potentiation of NMDA-mediated neurotransmission in VTA synapses (Borgland et al, 2006). As olanzapine has been shown to increase the expression of $c$-fos in orexincontaining cells in the hypothalamus (Fadel et al, 2002), one possibility is that olanzapine activates orexin-containing cells that project to the VTA and the orexin-1 receptor antagonist blocks the effects of orexin on A10 dopamine neurons. However, as haloperidol does not activate orexincontaining cells of the hypothalamus (Fadel et al, 2002), this pathway cannot mediate the effects of SB-334867 on the haloperidol-induced activation of A10 cells. Other possible sites of action of SB-334867 include areas that both send afferents to the VTA and also contain high densities of orexin-1 receptors. For example, the LC contains a high density of orexin-1 receptors (Hervieu et al, 2001), projects to the VTA (Phillipson, 1979), and its cells are excited by olanzapine (Dawe et al, 2001). However, as orexin-1 receptor antagonists do not block the actions of olanzapine in the LC (Figure 2), this pathway is not likely to be involved. The bed nucleus of the stria terminalis is another possible site of action of SB-334867 as it sends glutamergic projections to VTA dopamine neurons and also contains a high density of orexin-1 receptors (Hervieu et al, 2001; Georges and Aston-Jones, 2002). Still another possible site of action is the prefrontal cortex (PFC). Whereas the PFC has a relatively low proportion of orexin-1 receptors (Hervieu et al, 2001), PFC cells are known to send projections to A10 cells and have a significant influence on their activity (Sesack and Pickel, 1992; Carr and Sesack, 2000), and this pathway has been hypothesized to play an important role in the pathophysiology of schizophrenia (Sesack and Carr, 2002). Indeed, recent preliminary data indicate that orexin-1 receptor antagonists can block the effects of another atypical antipsychotic (clozapine) on Fos expression in the PFC (Deutch et al, 2005). Thus, blockade of the effects of an afferent input to A10 from the PFC is another possible mechanism for the results seen in the present study. Similar to the effects of SB-334867 on A10 cells, the locus of action of the blockade of the haloperidolinduced activation of A9 cells cannot be determined from this study. Interestingly, areas that are known to project to the SN do not contain a high level of orexin-1 receptors. The striatum is known to play an important role in the depolarization inactivation of A9 cells as acute transaction 
of the striatonigral afferents will reverse depolarization inactivation and restore A9 activity (Chiodo and Bunney, 1983). Thus, the striatum may be a final common pathway for actions of the orexin-1 receptors antagonist on the effects of haloperidol on A9 cells.

Recent studies indicate that there is a dissociable regulation of the activity of A10 dopamine neurons by two separate afferent systems. An inhibitory GABAergic afferent from the ventral pallidum (VP) regulates the population activity (ie, the number of spontaneously active cells) of A10 dopamine cells, whereas excitatory-glutamatergic and cholinergic afferents from the pedunculopontine tegmental nucleus regulates the burst firing of A10 dopamine neurons (Floresco et al, 2003). The input to A10 dopamine cells from the VP is under the influence of a GABA projection from the nucleus accumbens (NAc), which in turn is influenced by a projection from the ventral subiculum of the hippocampus (Floresco et al, 2001, 2003). When the inhibitory GABAergic input to the VTA from the VP is inactivated, there is a disinhibitory increase in the population activity of dopamine neurons, which activates a reserve pool of quiescent dopamine neurons (see Figures 3 and 4). Further, continuous inactivation of this pathway may play a role in the depolarization inactivation of dopamine neurons seen following repeated treatment with antipsychotics (see Figures 5 and 6). Thus, disinhibition of this input from the VP is likely to play a role in the effects of both acute and repeated administration of haloperidol and olanzapine observed in this study. Altering the activity of this VP input to the VTA may represent the final common pathway by which SB-334867 reverses the effects of haloperidol and olanzapine on A10 dopamine cell activity.

In addition to altering the actions of antipsychotic drugs on VTA activity, it is possible that orexin-1 antagonists could alter the activity of VTA neurons under normal physiological conditions. Activity of A10 dopamine cells has been hypothesized to be important for enabling of motor, cognitive, and motivational behavior (Schultz, 1998; Datla et al, 2002) and may be one pathway by which endogenous orexin enhances arousal. Indeed, recent data have shown that orexin increases dopamine efflux in the PFC via activation of the VTA (Vittoz and Berridge, 2006). Thus, it could be hypothesized that orexin-1 receptor antagonists would block the effects of physiological stimulation (such as might occur during periods of arousal) of this pathway in the behaving animal. Along these lines, A10 dopamine neurons are known to fire in bursts in response behaviorally salient stimuli (Schultz, 1998). Input from the laterodorsal tegmentum has recently been shown to be essential for this burst firing and the released dopamine has been hypothesized to encode reward prediction or indicate incentive salience (Berridge and Robinson, 1998; Lodge and Grace, 2006). As the orexin system has been hypothesized to play an important role in high-arousal environmental conditions (including feeding) (Sakurai et al, 1998; Espana et al, 2003), it would be interesting to see whether orexin-1 receptor antagonists could block the burst firing of A10 neurons that occurs in response to behaviorally salient stimuli, especially food reward.

Antipsychotic drugs have a very complex pharmacology and produce a number of well-documented effects in animals and humans. Additional work will be needed to determine whether orexin-1 (or orexin-2) receptor antagonists can block any other effects of antipsychotic drugs, including behavioral (eg activity in conditioned avoidance assays) or neurochemical (eg elevations in transmitter release) effects. In this regard, as mentioned above, it is interesting to note that a preliminary report indicates that orexin-1 receptor antagonists can block the effects of clozapine on Fos expression in the PFC (Deutch et al, 2005). Whether orexin-1 receptor antagonists can block the effects of antipsychotics on Fos expression in other brain areas (eg NAc) will need to be determined. In addition, tests with other selective orexin-1 antagonists are needed to confirm the pharmacological specificity of the effects reported here.

Orexin-A has been previously reported to increase the activity of LC cells following direct application to brainstem slices and iontophoretic application directly onto LC cells (Hagan et al, 1999; Bourgin et al, 2000; Murai and Akaike, 2005) and SB-334867 has been shown to block these effects (Soffin et al, 2002). The present study confirms and extends these findings by showing that i.c.v. administration of orexin-A can activate the LC and systemic administration of the selective orexin-1 receptor antagonist can reverse this effect. Olanzapine administration has also been previously demonstrated to increase the activity of LC neurons (Dawe et al, 2001; Seager et al, 2004). Administration of SB-334867 did not block the effects of olanzapine on LC neurons. These results indicate that orexin-1 receptor antagonists do not block all the effects of olanzapine and orexin-1 receptors are not involved in olanzapine's activation of LC neurons.

In conclusion, the selective orexin-1 receptor antagonist SB-334867 did not alter the number of spontaneously active A9 or A10 cells, but did reverse: (1) the increase in the number of spontaneously active A9 and/or A10 dopamine cells caused by the acute administration of haloperidol or olanzapine and (2) the decrease in the number of spontaneously active A9 and/or A10 dopamine cells caused by the chronic administration of haloperidol or olanzapine. These results indicate that activation of orexin-1 receptors plays an important role in the effects of antipsychotic drugs on dopamine neuronal activity and may play an important role in the clinical effects of antipsychotic drugs.

\section{ACKNOWLEDGEMENTS}

We acknowledge the contributions of Dr Laura Nisenbaum to the completion of this manuscript. We are employees and stock holders of Eli Lilly \& Co.

\section{REFERENCES}

Berridge KC, Robinson TE (1998). What is the role of dopamine in reward: hedonic impact, reward learning, or incentive salience? Brain Res Rev 28: 309-369.

Borgland SL, Taha SA, Sarti F, Fields HL, Bonci A (2006). Orexin A in the VTA is critical for the induction of synaptic plasticity and behavioral sensitization to cocaine. Neuron 49: 589-601.

Bourgin P, Huitron-Resendiz S, Spier AD, Fabre V, Morte B, Criado JR et al (2000). Hypocretin-1 modulates rapid eye movement sleep through activation of locus coeruleus neurons. J Neurosci 20: 7760-7765. 
Bunney BS, Grace AA (1978). Acute and chronic haloperidol treatment: comparison of effects on nigral dopaminergic cell activity. Life Sci 23: 1715-1728.

Bunney BS, Walters JR, Roth RH, Aghajanian GK (1973). Dopaminergic neurons: effects of antipsychotic drugs and amphetamine on single cell activity. J Pharm Exp Ther 185: 560-571.

Carr DB, Sesack SR (2000). Projections from the rat prefrontal cortex to the ventral tegmental area: target specificity in the synaptic associations with mesoaccumbens and mesocortical neurons. J Neurosci 20: 3864-3873.

Chiodo LA, Bunney BS (1983). Typical and atypical neuroleptics: differential effects of chronic administration on the activity of A9 and A10 midbrain dopaminergic neurons. J Neurosci 3: 1607-1619.

Datla KP, Ahier RG, Young AM, Gray JA, Joseph MH (2002). Conditioned appetitive stimulus increases extracellular dopamine in the nucleus accumbens of the rat. Eur J Neurosci 16: 1987-1993.

Dawe GS, Huff KD, Vandergriff JL, Sharp T, O’Neill MJ, Rasmussen $\mathrm{K}$ (2001). Olanzapine activates the rat locus coeruleus: in vivo electrophysiology and c-Fos immunoreactivity. Biol Psychiatry 50: $510-520$

Deutch AY, Jackson LL, Bubser M (2005). Disruption of orexin/ hypocretin signaling blocks the effects of clozapine on the prefrontal cortex. Schiz Bull 31: 510.

Espana RA, Valentino RJ, Berridge CW (2003). Fos immunoreactivity in hypocretin-synthesizing and hypocretin-1 receptor-expressing neurons: effects of diurnal and nocturnal spontaneous waking, stress and hypocretin-1 administration. Neuroscience 121: 201-217.

Fadel J, Bubser M, Deutch AY (2002). Differential activation of orexin neurons by antipsychotic drugs associated with weight gain. J Neurosci 22: 6742-6746.

Fadel J, Deutch AY (2002). Anatomical substrates of orexindopamine interactions: lateral hypothalamic projections to the ventral tegmental area. Neuroscience 111: 379-387.

Floresco SB, Todd CL, Grace AA (2001). Glutamatergic afferents from the hippocampus to the nucleus accumbens regulate activity of ventral tegmental area dopamine neurons. J Neurosci 21: 4915-4922.

Floresco SB, West AR, Ash B, Moore H, Grace AA (2003). Afferent modulation of dopamine neuron firing differentially regulates tonic and phasic dopamine transmission. Nat Neurosci 6: 968-973.

Georges F, Aston-Jones G (2002). Activation of ventral tegmental area cells by the bed nucleus of the stria terminalis: a novel excitatory amino acid input to midbrain dopamine neurons. J Neurosci 22: 5173-5187.

Graham AW, Aghajanian GK (1971). Effects of amphetamine on single cell activity in a catecholamine nucleus, the locus coeruleus. Nature 234: 100-102.

Gueudet C, Santucci V, Soubrie P, Le Fur G (1999). Blockade of neurokinin3 receptors antagonizes drug-induced population response and depolarization block of midbrain dopamine neurons in guinea pigs. Synapse 33: 71-79.

Hagan JJ, Leslie RA, Patel S, Evans ML, Wattam TA, Holmes S et al (1999). Orexin A activates locus coeruleus cell firing and increases arousal in the rat. Proc Natl Acad Sci USA 96: 10911-10916.

Hervieu GJ, Cluderay JE, Harrison DC, Roberts JC, Leslie RA (2001). Gene expression and protein distribution of the orexin-1 receptor in the rat brain and spinal cord. Neuroscience 103: 777-797.
Korotkova TM, Sergeeva OA, Eriksson KS, Haas HL, Brown RE (2003). Excitation of ventral tegmental area dopaminergic and nondopaminergic neurons by orexins/hypocretins. J Neurosci 23: 7-11.

Lodge DJ, Grace AA (2006). The laterodorsal tegmentum is essential for burst firing of ventral tegmental area dopamine neurons. Proc Natl Acad Sci USA 103: 5167-5172.

Meltzer HY, Arvanitis L, Bauer D, Rein W, Meta-Trial Study Group (2004). Placebo-controlled evaluation of four novel compounds for the treatment of schizophrenia and schizoaffective disorder. Am J Psychiatry 161: 975-984.

Murai Y, Akaike T (2005). Orexins cause depolarization via nonselective cationic and $\mathrm{K}^{+}$channels in isolated locus coeruleus neurons. Neurosci Res 51: 55-65.

Phillipson OT (1979). Afferent projections to the ventral tegmental area of Tsai and interfascicular nucleus: a horseradish peroxidase study in the rat. J Comp Neurol 187: 117-143.

Piper DC, Upton N, Smith MI, Hunter AJ (2000). The novel brain neuropeptide, orexin-A, modulates the sleep-wake cycle of rats. Eur J Neurosci 12: 726-730.

Sakurai T, Amemiya A, Ishii M, Matsuzaki I, Chemelli RM, Tanaka $\mathrm{H}$ et al (1998). Orexins and orexin receptors: a family of hypothalamic neuropeptides and $\mathrm{G}$ protein-coupled receptors that regulate feeding behavior. Cell 92: 573-585.

Schultz W (1998). Predictive reward signal of dopamine neurons. J Neurophysiol 80: 1-27.

Seager MA, Huff KD, Barth VN, Phebus LA, Rasmussen K (2004). Fluoxetine administration potentiates the effect of olanzapine on locus coeruleus neuronal activity. Biol Psychiatry 55: 1103-1109.

Sesack SR, Carr DB (2002). Selective prefrontal cortex inputs to dopamine cells: implications for schizophrenia. Physiol Behav 77: 513-517.

Sesack SR, Pickel VM (1992). Prefrontal cortical efferents in the rat synapse on unlabeled neuronal targets of catecholamine terminals in the nucleus accumbens septi and on dopamine neurons in the ventral tegmental area. J Comp Neurol 320: 145-160.

Smart D, Jerman JC, Brough SJ, Neville WA, Jewitt F, Porter RA (2000). The hypocretins are weak agonists at recombinant human orexin-1 and orexin-2 receptors. $B r J$ Pharmacol 129: $1289-1291$.

Smart D, Jerman JC, Brough SJ, Rushton SL, Murdock PR, Jewitt F et al (1999). Characterization of recombinant human orexin receptor pharmacology in a Chinese hamster ovary cell-line using FLIPR. Br J Pharmacol 128: 1-3.

Smart D, Sabido-David C, Brough SJ, Jewitt F, Johns A, Porter RA et al (2001). SB-334867-A: the first selective orexin-1 receptor antagonist. Br J Pharmacol 132: 1179-1182.

Soffin EM, Evans ML, Gill CH, Harries MH, Benham CD, Davies CH (2002). SB-334867-A antagonises orexin mediated excitation in the locus coeruleus. Neuropharmacology 42: 127-133.

Stockton ME, Rasmussen K (1996). Olanzapine, a novel atypical antipsychotic, reverses d-amphetamine-induced inhibition of midbrain dopamine cells. Psychopharmacol 124: 50-56.

van den Pol AN, Gao XB, Obrietan K, Kilduff TS, Belousov AB (1998). Presynaptic and postsynaptic actions and modulation of neuroendocrine neurons by a new hypothalamic peptide, hypocretin/orexin. J Neurosci 18: 7962-7971.

Vittoz NM, Berridge CW (2006). Hypocretin/orexin selectively increases dopamine efflux within the prefrontal cortex: involvement of the ventral tegmental area. Neuropsychopharmacology 31: 384-395.

White FJ, Wang RY (1983). Differential effects of classical and atypical antipsychotic drugs on A9 and A10 dopamine neurons. Science 221: 1054-1057. 